\title{
The Proportion of Blue Light from Light-emitting Diodes Alters Microgreen Phytochemical Profiles in a Species-specific Manner
}

\author{
Qinglu Ying, Chase Jones-Baumgardt, and Youbin Zheng \\ School of Environmental Sciences, University of Guelph, 50 Stone Road East, \\ Guelph, ON, N1G 2W1, Canada

\section{Gale Bozzo \\ Department of Plant Agriculture, University of Guelph, 50 Stone Road East, Guelph, ON, N1G 2W1, Canada}

Additional index words. anthocyanin, ascorbate, carotenoid, chlorophyll, light quality, phenolics

\begin{abstract}
Microgreens are specialty vegetables that contain human health-promoting phytochemicals. Typically, microgreens are cultivated in controlled environments under red and blue light-emitting diodes (LEDs). However, the impact of varying the proportions of these light qualities on the composition of diverse phytochemicals in indoorgrown microgreens is unclear. To address this problem, the levels of chlorophylls, carotenoids, ascorbates, phenolics, anthocyanins, and nitrate were examined in arugula (Eruca sativa L.), 'Red Russian' kale [Brassica napus L. subsp. napus var. pabularia (DC.) Alef.], 'Mizuna' mustard (Brassica juncea L.), and red cabbage (Brassica oleracea L. var. capitata f. rubra) microgreens following cultivation under LEDs supplying varying proportions of blue light $(5 \%$ to $30 \%)$ and red light $(70 \%$ to $95 \%)$. Varying the proportion of blue light did not affect the extractable levels of total chlorophyll, total carotenoids, or nitrate in all four microgreen species. Generally, the levels of reduced and total ascorbate were greatest in arugula, kale, and mustard microgreens at $20 \%$ blue light, and a minor decrease was apparent at $30 \%$ blue light. These metabolite profiles were not impacted by the blue light percentage in red cabbage. Kale and mustard accumulated more total phenolics at $30 \%$ blue light than all other blue light regimens; however, this phytochemical attribute was unaffected in arugula and red cabbage. The total anthocyanin concentration increased proportionally with the percentage of supplied blue light up to $30 \%$ in all microgreens, with the exception of mustard. Our research showed that $20 \%$ blue light supplied from LED arrays is ideal for achieving optimal levels of both reduced and total ascorbate in all microgreens except red cabbage, and that $30 \%$ blue light promotes the greatest accumulation of total anthocyanin in indoor-grown Brassicaceae microgreens, with the exception of mustard.
\end{abstract}

Microgreens are a group of specialty crops that are normally harvested when both cotyledons have expanded and the first true leaves start to emerge (Treadwell et al.,

Received for publication 17 Aug. 2020. Accepted for publication 15 Sept. 2020.

Published online 17 December 2020

We are grateful for the financial support awarded to Youbin Zheng by the Natural Sciences and Engineering Research Council of Canada and the Greenbelt Microgreens Ltd. We also thank Heliospectra $\mathrm{AB}$ (Gothenburg, Sweden) for providing LED lighting technologies for this study. We acknowledge Dave Llewellyn for his excellent technical support and fruitful discussion pertaining to cultivation of microgreens under LED. Many thanks to Gordon Hoover for technical expertise regarding HPLC analysis of ascorbate metabolites. G.B. is the corresponding author. E-mail: gbozzo@ uoguelph.ca.

This is an open access article distributed under the CC BY-NC-ND license (https://creativecommons. org/licenses/by-nc-nd/4.0/).
2016). Microgreens are a rich source of health-promoting phytochemicals compared with their corresponding mature plants (Xiao et al., 2012). Phytochemicals that are present in microgreens, specifically in those of the Brassicaceae family, include ascorbate (i.e., vitamin C), chlorophylls, carotenoids, phenolics, and anthocyanins (Xiao et al., 2019). Although light harvesting pigments such as chlorophylls are not well-known for human health benefits, the consumption of the other aforementioned phytochemicals can potentially reduce the risk of chronic and degenerative diseases (Zhang et al., 2015). Carotenoids include carotenes and xanthophylls that function as accessory photosynthetic pigments in plants, some of which are converted in humans to vitamin A, which is crucial for vision, or as antioxidants that can prevent cancer and other chronic diseases (Rao and Rao, 2007; Thoma et al., 2020). Another well-known plant-derived antioxidant is ascorbate. In humans, ascorbate defi- ciency is linked to scurvy, and dietary ascorbate regulates collagen formation and iron uptake and is involved in epigenetic control of various diseases (Macknight et al., 2017). Phenolic compounds that occur in plants include simple aromatic compounds such as hydroxycinnamic acids and complex polyphenols like anthocyanin pigments. Apart from their antioxidant benefits, some of these phenolic molecules have antiinflammatory effects in humans (Zhang and Tsao, 2016). In addition, microgreens contain lower levels of nitrate compared with mature leafy vegetables (Pinto et al., 2015). From the standpoint of human health, the effect of dietary nitrate has been the subject of much debate. There is evidence that nitrate derived from vegetables in the diet can provide cardioprotective benefits, including the capacity to lower blood pressure (Machha and Schechter, 2012). There is some concern that an excess of food-derived nitrate can be problematic because it is sequentially converted to nitrite and nitrosamine in the body; furthermore, the accumulation of the latter is associated with an increased risk of certain types of cancer (Bian et al., 2015; Mensinga et al., 2003).

Microgreens can be grown in indoor environments with electrical lighting as the sole light source, which circumvents the restrictions of ambient light on plant growth, such as biomass accumulation (Darko et al., 2014). LED technology has many advantages over traditional light sources (e.g., high-pressure sodium light and fluorescent light), including energy efficiency, low heat output, long operating lifetime, and lower environmental cost (Bourget, 2008). Moreover, LEDs afford the opportunity to modulate spectral composition to optimize the morphology and phytochemical distribution of indoor-grown plants (Bian et al., 2015; Yeh and Chung, 2009). It is known that blue light (400-500 $\mathrm{nm})$ and red light $(600-700 \mathrm{~nm})$ are readily absorbed by leaves and used for photosynthesis (McCree, 1972). Red light supplemented with blue light increases photosynthetic capacity and biomass accumulation in plant seedlings (Hogewoning et al., 2010; Tanaka et al., 1998). The combination of blue and red LEDs is widely used for horticultural crop production, including microgreens (JonesBaumgardt et al., 2019; Massa et al., 2008; Ying et al., 2020).

Typically, the photosynthetic photon flux density $(P P F D)$ that is supplied to leafy green vegetables that are cultivated indoors can be as high as $300 \mu \mathrm{mol} \cdot \mathrm{m}^{-2} \cdot \mathrm{s}^{-1}$ (Thoma et al., 2020). For Brassicaceae microgreens grown under blue and red LEDs, PPFDs of 300 to $400 \mu \mathrm{mol} \cdot \mathrm{m}^{-2} \cdot \mathrm{s}^{-1}$ are optimal for yield and aesthetic quality (Jones-Baumgardt et al., 2019). However, high blue:red light ratios are known to decrease the growth and yield of herbs (Dou et al., 2017). A recent study found that LEDs supplying red:blue light ratios of $95 \%$ red:5\% blue to $85 \%$ red: $15 \%$ blue are optimal for hypocotyl length and cotyledon area in kale and mustard microgreens; however, a reduction in these morphological 
attributes is apparent at higher blue light percentages (Ying et al., 2020). In addition, microgreens amass more reddish than green surface coloration when the proportion of blue light in the LED array is increased from $5 \%$ to $30 \%$ (Ying et al., 2020). These morphological changes may be associated with modifications in plant vitamins and secondary metabolites under increasing proportions of blue light supplied by LEDs and potentially affect the nutritional quality.

Light quality has a pronounced effect on the levels of phytochemicals that accumulate within plants under controlled environments (Bian et al., 2015). Previous studies indicated that some phytochemical profiles vary with the proportion of blue light supplied by LEDs, albeit in a manner that is dependent on the plant species and/or developmental stage, including in their microgreen forms. For example, the amount of chlorophyll in cucumber (Cucumis sativus L.) leaves is elevated with increases in blue light proportions from $0 \%$ to $50 \%$ supplied from red:blue LEDs (Hogewoning et al., 2010). In contrast, there is no difference in the chlorophyll concentrations in tomato (Solanum lycopersicum L.), salvia (Salvia splendens Sellow ex Schult), or impatiens (Impatiens walleriana Hook.f.) seedlings cultivated under LEDs with varying blue light in the range of $6 \%$ to $50 \%$ (Wollaeger and Runkle, 2015). Increasing the percentage of blue light from $0 \%$ to $33 \%$ enhances the total carotenoid concentration in beet (Beta vulgaris L.) microgreens, but not in parsley [Petroselinum crispum (Mill.) Fuss] or mustard [Brassica juncea (L.) Czern.] microgreens (Samuoliene et al., 2017). Similarly, the proportion of blue light has no effect on ascorbate levels in rapeseed (Brassica napus L.) plantlets ( $\mathrm{Li}$ et al., 2013); however, ascorbate tends to be present at higher levels in lettuce (Lactuca sativa L.) cultivated under LEDs supplying $75 \%$ blue: $25 \%$ red light relative to those delivering $25 \%$ blue: $75 \%$ red and $50 \%$ blue:50\% red light (Zha et al., 2020). The impact of blue light on ascorbate metabolism has not been widely explored in microgreens. It is worth mentioning that the study by $\mathrm{Li}$ et al. (2013) assessed ascorbate using a spectrophotometric analysis of plantlet extracts. This is not ideal because a spectrophotometric analysis of plant ascorbate requires higher specificity based on ascorbate oxidasecoupled assays (Queval and Noctor, 2007) or spectrophotometric detection following high-performance liquid chromatography (HPLC) separation (Flaherty et al., 2018). Increased levels of total phenolic compounds in lettuce are elevated as the proportion of blue light is increased $0 \%$ to $47 \%$ (Son and Oh, 2013). Although the alteration of anthocyanin concentrations in microgreens in response to the increasing proportion of blue light is not well-understood, anthocyanin levels are enhanced in baby red lettuce cultivated under cool white fluorescent lamps supplemented with blue LEDs ( $\mathrm{Li}$ and Kubota, 2009). In addition, anthocyanin accumulates in the leaves of mature pepper
(Capsicum annuum L.) plants cultivated under intermittent illumination with a high percentage blue light (Hoffmann et al., 2016). Although the aforementioned studies have examined the impact of blue light on select phytochemicals, a comprehensive analysis of the impact of this light quality on simultaneous alterations of photosynthetic pigments, ascorbate metabolites, phenolics, and anthocyanins as well as nitrate in Brassicaceae microgreens has not been explored. Herein, we investigated the effect of solesource LED arrays supplying various proportions of blue light, specifically $5 \%$ to $30 \%$ with the remainder consisting of red light, on the levels of total chlorophyll and its individual components, total carotenoid concentrations, total phenolic concentrations, total anthocyanin concentrations, reduced ascorbate concentrations, dehydroascorbate concentrations, and nitrate concentrations in arugula, kale, mustard, and red cabbage microgreens.

\section{Materials and Methods}

Experimental materials and design. The experiment was conducted in a walk-in growth chamber with a controlled environment [7.3 $\mathrm{m} \times 4.0 \mathrm{~m} \times 2.5 \mathrm{~m}$ (length $\times$ width $\times$ height)] at the University of Guelph. Details related to the experimental design and environmental growth conditions are described in a previous report (Ying et al., 2020). Briefly, seeds of arugula (Eruca sativa L.), 'Red Russian' kale [Brassica napus L. subsp. napus var. pabularia (DC.) Alef.], 'Mizuna' mustard (Brassica juncea L.), and red cabbage (Brassica oleracea L. var. capitata f. Rubra) were separately sown on organic substrates supplied by Greenbelt Microgreens Inc. (Lynden, ON, Canada) in fiber trays $(23.5 \mathrm{~cm} \times 48.5 \mathrm{~cm} \times 3.5 \mathrm{~cm})$. After watering, the sown microgreen trays were randomly placed in six separate compartments within the growth chamber under different lighting treatments. Opaque white vertical blinds separated the light quality treatment compartments within the growth chamber. Each lighting treatment compartment contained two Heliospectra LED arrays (LX602C; Heliospectra AB, Gothenburg, Sweden) that were positioned $36 \mathrm{~cm}$ apart in the center of the plot area and $56.5 \mathrm{~cm}$ above the substrate in the seed trays. The experiment comprised six light quality treatments with varying proportions of blue (445 nm peak) and red (660 nm peak) light supplied from the aforementioned LED arrays. These six LED regimens were as follows: 5\% blue light and 95\% red light; $10 \%$ blue light and $90 \%$ red light; $15 \%$ blue light and $85 \%$ red light; $20 \%$ blue light and $80 \%$ red light; $25 \%$ blue light and $75 \%$ red light; and $30 \%$ blue light and $70 \%$ red light. All lighting treatments had a fixed PPFD of 300 $\mu \mathrm{mol} \cdot \mathrm{m}^{-2} \cdot \mathrm{s}^{-1}$ and were applied for a $16-\mathrm{h}$ photoperiod. For each light quality treatment, $P P F D$ and spectral distribution were measured at 25 separate canopy level positions, as described previously (Ying et al., 2020). For simplicity, henceforth, all LED quality treatments are referred to as the percentage of supplied blue light. For each lighting treatment, there were four trays of sown seeds, with each tray containing only one of the aforementioned species. The experiment was a randomized complete block design with six light treatments within a single chamber with a controlled environment. The temperature in the walk-in chamber with a controlled environment was set and maintained at $21{ }^{\circ} \mathrm{C}$ during the light period (10:00 AM to 2:00 AM) and $17{ }^{\circ} \mathrm{C}$ during the dark period. The relative humidity was maintained at $\approx 80 \%$ over the course of the experiment. The temperature and relative humidity were monitored by an automated system (Argus Controls Systems Ltd., Surrey, BC, Canada). All growing substrates were top-irrigated at least once each day using tap water until the appearance of visible drainage. A total of three separate light quality experiments were performed.

Tissue sampling for phytochemical analyses. For each microgreen species and light quality treatment within each experiment, three subsamples ( $\approx 5$ g per subsample) of aboveground plant parts, including cotyledons, stems, and first true leaves, were collected $10 \mathrm{~d}$ after sowing for kale and red cabbage and $11 \mathrm{~d}$ after sowing for arugula and mustard. The harvested microgreens were immediately flash-frozen in liquid $\mathrm{N}_{2}$ and pulverized with a prechilled mortar and pestle. The flash-frozen microgreen powders were stored at $-80{ }^{\circ} \mathrm{C}$ for up to 8 months before phytochemical analyses. Unless otherwise mentioned, all chemicals required were purchased from Sigma-Aldrich Inc. (Oakville, ON, Canada). Glacial acetic acid, methanol, and ortho-phosphoric acid were obtained from Thermo-Fisher Scientific (Mississauga, ON, Canada).

Chlorophyll and carotenoids. To analyze chlorophyll and carotenoids from each microgreen LED regimen treatment replicate, cryogenic microgreen powder $(20 \mathrm{mg})$ was transferred to a prechilled Eppendorf tube and resuspended in $1 \mathrm{~mL}$ of ice-cold $100 \%$ methanol. The sample was vortexed for $1 \mathrm{~min}$ and incubated on ice under darkness for $\approx 10 \mathrm{~min}$, followed by a second mixing by vortexing before centrifugation at $21,000 \mathrm{~g}_{\mathrm{n}}$ for $5 \mathrm{~min}$ at $4{ }^{\circ} \mathrm{C}$. The supernatant was collected and serial dilutions (up to three times) in a final volume of $200 \mu \mathrm{L}$ were prepared in $100 \%$ ice-cold methanol. The methanolic extract and its dilutions were transferred to a 96-well microplate reader (SpectraMax 384 Plus; Molecular Devices, Sunnyvale, CA) and absorbance readings were performed at 665,652 , and $476 \mathrm{~nm}$ for chlorophyll $a$, chlorophyll $b$, and carotenoids, respectively. The chlorophyll $a$, chlorophyll $b$, and total carotenoid concentrations were calculated using the equations for methanolic solutions described by Lichtenthaler and Buschmann (2001).

Ascorbate metabolites. An established method reported by Flaherty et al. (2018) was used to assess reduced ascorbate, dehydroascorbate, 


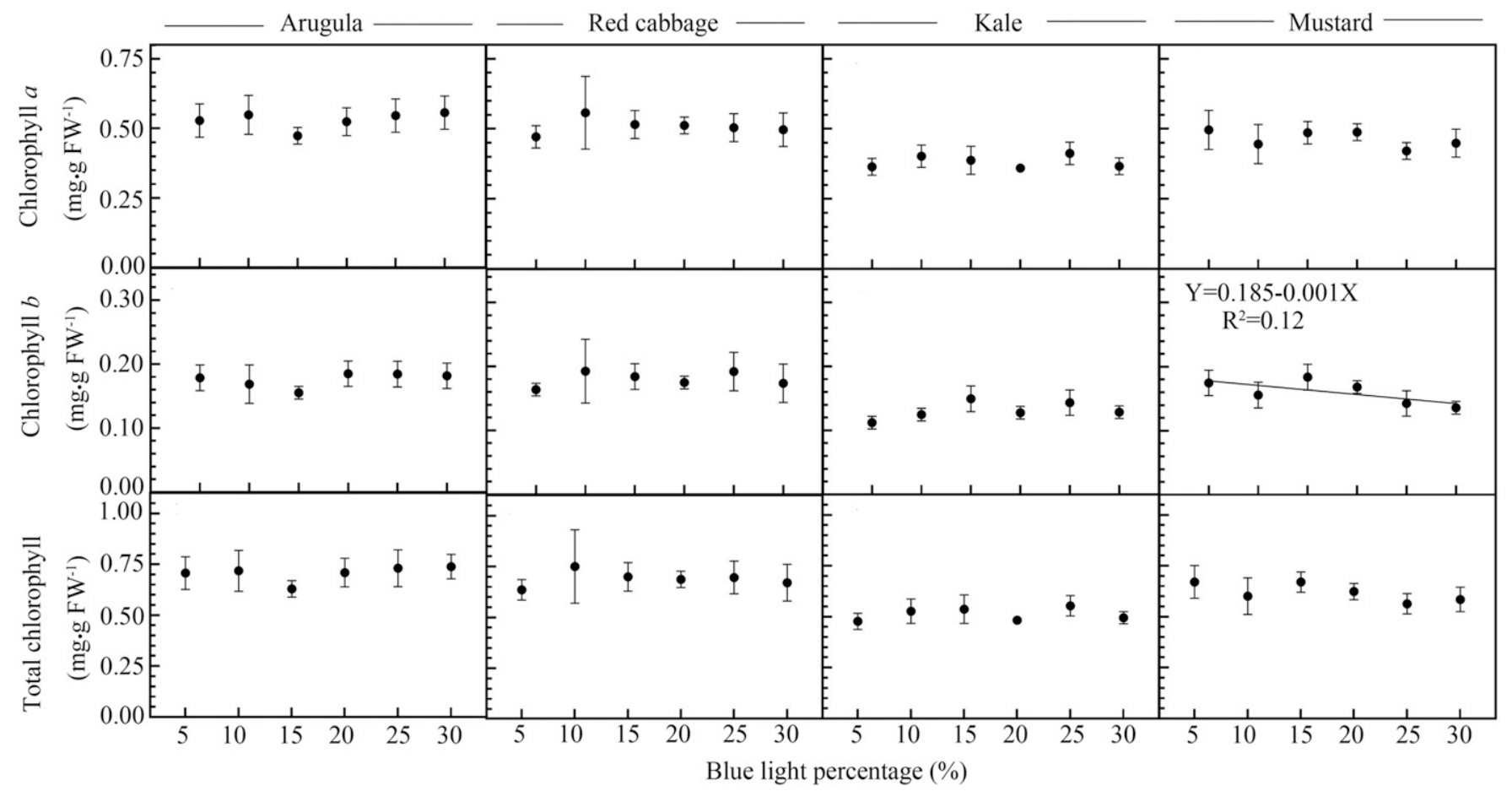

Fig. 1. The impact of light quality on chlorophyll $a$, chlorophyll $b$, and total chlorophyll concentrations of arugula (Eruca sativa L.), 'Red Russian' kale [Brassica napus L. subsp. napus var. pabularia (DC.) Alef.], 'Mizuna' mustard (Brassica juncea L.), and red cabbage (Brassica oleracea L. var. capitata f. rubra). In all cases, microgreens were cultivated under a constant photosynthetic photon flux density of $300 \mu \mathrm{mol} \cdot \mathrm{m}^{-2} \cdot \mathrm{s}^{-1}$ with varying percentages of blue light. Data represent the mean $\pm \mathrm{SE}$ of three separate experiments. A linear regression line represented by a solid black line is shown where the effect of the blue light percentage was significant at $P \leq 0.05 . R^{2}$ represents the corresponding determination coefficient.

and total ascorbate concentrations. These metabolites were extracted from frozen microgreen powders $(200 \mathrm{mg})$ after grinding the tissue with an ice-cold mortar and pestle with $500 \mu \mathrm{L}$ of $6 \%(\mathrm{w} / \mathrm{v})$ meta-phosphoric acid in the presence of acid-washed silica sand and then centrifuged at $13,000 \mathrm{~g}_{\mathrm{n}}$ for $10 \mathrm{~min}$ at $4{ }^{\circ} \mathrm{C}$. The supernatant was filtered through a $0.45-\mu \mathrm{m}$ polytetrafluoroethylene filter (diameter, $13 \mathrm{~mm}$; Mandel Scientific Inc., Guelph, $\mathrm{ON}$, Canada). The preparation containing reduced ascorbate was analyzed by HPLC as described here. To analyze total ascorbate concentrations, the supernatant was subjected to a chemical reduction to promote the conversion of dehydroascorbate to reduced ascorbate. A $50-\mu \mathrm{L}$ aliquot of the supernatant was combined with $25 \mu \mathrm{L}$ of $400 \mathrm{~mm}$ dithiothreitol (DTT) in a 2-M Tris base. After incubating for $15 \mathrm{~min}$ at $24{ }^{\circ} \mathrm{C}, 25 \mu \mathrm{L}$ of $8.5 \%(\mathrm{v} / \mathrm{v})$ orthophosphoric acid was added to end the reduction step.

The total and reduced ascorbate preparations were analyzed by HPLC; $1 \mu \mathrm{L}$ of the non-DTT-treated extract (reduced ascorbate concentration) and $2 \mu \mathrm{L}$ of the DTT-treated extract (total ascorbate concentration) were separately analyzed using the HPLC procedure. The aforementioned extracts were injected on a Restek Ultra Aqueous C18 column $(150 \times 4.6 \mathrm{~mm}, 5 \mu \mathrm{m}$ particle; Chromatographics Specialties Inc, ON, Canada) attached to an Agilent 1200 HPLC (Agilent Technologies, Mississauga, ON, Canada) system and thermostatted to $20^{\circ} \mathrm{C}$. Ascorbate was eluted isocratically with $20 \mathrm{~mm}$ ortho- phosphoric acid at a flow rate of $1 \mathrm{~mL} \cdot \mathrm{min}^{-1}$ over $10 \mathrm{~min}$. The absorbance of the eluate was monitored at $254 \mathrm{~nm}$ and ascorbate peaks were compared with a known range of authentic L-ascorbate (Sigma-Aldrich Inc.) standard for quantification of the reduced ascorbate concentration in the DTT-free extract and the total ascorbate concentration in the DTT-treated extract. The dehydroascorbate concentration was calculated by subtracting the ascorbate detected in the DTT-free extract from that apparent in the DTT-treated extract. The levels of ascorbate in both DTT and non-DTT containing extracts were corrected by assessing the recovery of a known amount of authentic reduced ascorbate $(377-778 \mathrm{nmol})$ that was added to a representative duplicate extract. The HPLC analysis revealed that the recovery of the reduced ascorbate that was spiked into the ascorbate extract was in the range of $70 \%$ to $97 \%$.

Total phenolic concentration. The total phenolic concentration was evaluated according to the procedure described by Ainsworth and Gillespie (2007), with some modifications. Approximately $20 \mathrm{mg}$ of frozen microgreen powder was transferred to a 2-mL Eppendorf tube, resuspended in $1 \mathrm{~mL}$ ice-cold $100 \%$ methanol, and vortexed twice for $1 \mathrm{~min}$. The sample was then centrifuged at $13,000 \mathrm{~g}$ for $5 \mathrm{~min}$ at $4{ }^{\circ} \mathrm{C}$. A $25-\mu \mathrm{L}$ aliquot of the supernatant and dilutions prepared in $100 \%$ methanol were separately dispensed into wells of a 96-well microplate. Thereafter, $125 \mu \mathrm{L}$ of $10 \%(\mathrm{v} / \mathrm{v})$ Folin-Ciocalteau reagent was added to each well, and the plate was incubated at room temperature for 10 min, followed by the addition of $125 \mu \mathrm{L}$ of $7.5 \%$ (w/v) $\mathrm{Na}_{2} \mathrm{CO}_{3}$. The absorbance was measured at $765 \mathrm{~nm}$ using a SpectraMax 384 Plus microplate reader, and the total phenolic concentration was compared with an authentic gallic acid standard curve ranging from 0.018 to $0.6 \mathrm{mg} \cdot \mathrm{mL}^{-1}$.

Total anthocyanin concentration. For each microgreen and its light quality treatment replicate subsample, anthocyanins were extracted with acidified methanol according to the method of Roepke and Bozzo (2015). During the extraction process, $100 \mathrm{mg}$ of frozen microgreen powder was combined with $500 \mu \mathrm{L}$ of methanol:acetic acid:Milli-Q water $(9: 1: 10, \mathrm{v} / \mathrm{v} / \mathrm{v})$. The homogenate was vortexed for $1 \mathrm{~min}$, agitated on a nutator (Adams Nutator; Becton, Dickinson, and Company, Franklin Lakes, NJ) for $20 \mathrm{~min}$, and then centrifuged at $16,000 g_{\mathrm{n}}$ for $10 \mathrm{~min}$. The supernatant was collected and the residue was re-extracted twice as described previously. The supernatants from each successive extraction were pooled and partitioned against an equivalent volume of chloroform for the removal of chlorophyll. The $1.5-\mathrm{mL}$ acidified methanol phase was collected and dried in a speedvac (Savant SC100 Speed Vac Concentrator; Thermo Fisher Scientific). The anthocyanin residue was dissolved in $200 \mu \mathrm{L}$ of methanol containing $0.1 \% \mathrm{HCL}(\mathrm{v} / \mathrm{v})$. Thereafter, the absorption was measured at $530 \mathrm{~nm}$ with a SpectraMax 384 Plus microplate reader. The total anthocyanin content was expressed 


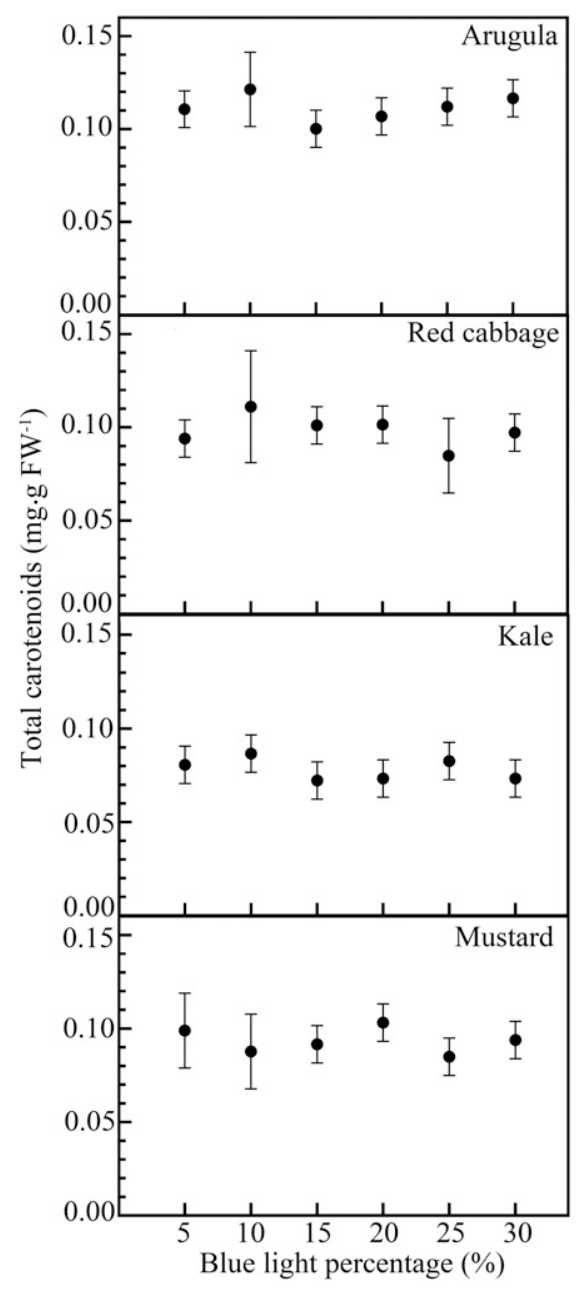

Fig. 2. The impact of light quality on total carotenoid concentrations of arugula (Eruca sativa L.), 'Red Russian' kale [Brassica napus L. subsp. napus var. pabularia (DC.) Alef.], 'Mizuna' mustard (Brassica juncea L.), and red cabbage (Brassica oleracea L. var. capitata $\mathrm{f}$ rubra). In all cases, microgreens were cultivated under a constant photosynthetic photon flux density of $300 \mu \mathrm{mol} \cdot \mathrm{m}^{-2} \cdot \mathrm{s}^{-1}$ with varying percentages of blue light. Data represent the mean \pm SE of three separate experiments. For each microgreen species, data were analyzed using a regression analysis, but there was no significant effect of the blue light percentage on total carotenoid concentrations.

as cyanidin 3-O-glucoside equivalents using a molar absorptivity $(\varepsilon)$ of $34,300 \mathrm{~L} \cdot \mathrm{mol}^{-1} \cdot \mathrm{cm}^{-1}$ (Siegelman and Hendricks, 1958).

Nitrate. The nitrate concentration in microgreens was analyzed using a microplate spectrophotometer method developed by Hachiya and Okamoto (2017). For each microgreen LED light quality treatment experimental replicate, $50 \mathrm{mg}$ of frozen microgreen powder was transferred to a microcentrifuge tube and combined with $500 \mu \mathrm{L}$ Milli-Q water, followed by incubation in a boiling water bath for $20 \mathrm{~min}$. After cooling to room temperature, the sample was centrifuged at $20,400 g_{n}$ for $10 \mathrm{~min}$ at room temperature. A $10-\mu \mathrm{L}$ aliquot of the extract was mixed with $40 \mu \mathrm{L}$ of $0.05 \%(\mathrm{w} / \mathrm{v})$ salicylic acid in sulfuric acid, followed by incubation at room temperature for $20 \mathrm{~min}$. Thereafter, $1 \mathrm{~mL}$ of $8 \%(\mathrm{w} / \mathrm{v}) \mathrm{NaOH}$ was added to each sample. The absorbance was measured at $410 \mathrm{~nm}$ with a SpectraMax 384 Plus microplate reader and compared with a nitrate standard curve ranging from 12.65 to $1600 \mu \mathrm{g} \cdot \mathrm{mL}^{-1}$. For each sample, nonspecific absorbance was estimated by incubating the aqueous extract with $40 \mu \mathrm{L}$ of sulfuric acid. To determine the amount of nitrate per microgreen sample, the nonspecific absorbance was subtracted from the absorbance of an assay performed in the presence of salicylic acid.

Statistical analysis. The relationships between alterations in phytochemical concentrations in each microgreen as a function of blue light percentage treatment were determined using regression analyses. To this end, linear and quadratic regressions for phytochemical data corresponding to experimental treatment replicates and their subsamples were established with SPSS software (version 25.0; IBM, Armonk, NY). Data were analyzed for normality of residuals and homoscedasticity by using the Shapiro-Wilk and Levene test, respectively. When applicable, heteroscedasticity of the data was verified with residual plots.

\section{Results}

Chlorophyll and carotenoid concentrations. Altering the percentage of blue light supplied from LEDs delivering a PPFD of 300 $\mu \mathrm{mol} \cdot \mathrm{m}^{-2} \cdot \mathrm{s}^{-1}$ had no effect on the concentrations of total chlorophyll and chlorophyll $a$ for all four microgreen species (Fig. 1). The average total chlorophyll contents across all six blue light treatments were $0.71,0.51$, 0.62 , and $0.69 \mathrm{mg} \cdot \mathrm{g}^{-1}$ fresh weight (FW) for arugula, kale, mustard, and red cabbage, respectively. Similarly, the blue light percentage supplied from LEDs had no effect on chlorophyll $b$, with the exception of mustard. Therefore, the chlorophyll $b$ concentration in mustard microgreens cultivated under $30 \%$ blue light was $14 \%$ smaller than that in those cultivated under 5\% blue light (Fig. 1). The total carotenoid concentration was similar across all LED light treatments, irrespective of species (Fig. 2). The average concentration of this phytochemical was $0.1 \mathrm{mg} \cdot \mathrm{g}^{-1}$ FW across all four microgreens and their light quality treatments.

Ascorbate metabolite concentrations. The effect of altering the blue light percentage supplied from sole-source LEDs on ascorbate metabolite composition in microgreens varied with the species (Fig. 3). For red cabbage, the reduced ascorbate concentration was comparable across all light quality treatments. For the other microgreens, the concentrations of reduced and total ascorbate concentrations increased $13 \%$ to $29 \%$ in microgreens cultivated under $20 \%$ blue light relative to $5 \%$ blue light. Thereafter, $9 \%$ to $11 \%$ lower concentrations of reduced ascorbate and $7 \%$ to $15 \%$ lower total ascorbate levels were apparent at $30 \%$ blue light rela- tive to these maximal levels (Fig. 3). Dehydroascorbate levels were unaffected by the percentage of blue light with the exception of arugula, which was $200 \%$ to $344 \%$ greater under blue light percentages of $15 \%$ to $20 \%$ relative to the smallest levels detected at $5 \%$ and $30 \%$ blue light. Dehydroascorbate accounted for $3 \%$ to $13 \%$ of the total ascorbate in the tested microgreen species.

Total phenolic and total anthocyanin concentrations. The total phenolic concentration of microgreens was affected by light quality, although in a species-dependent manner (Fig. 4). For kale, an increased proportion of blue light culminated in more total phenolics; for example, cultivation under $30 \%$ blue light yielded an $18 \%$ greater total phenolic concentration than that apparent under 5\% blue light. Similarly, the concentration of total phenolics in mustard microgreens increased linearly with elevated proportions of blue light; levels detected at $30 \%$ blue light were $24 \%$ greater than those apparent in the lowest blue light percentage treatment. The concentrations of total phenolics in red cabbage and arugula were not impacted by varying the blue light percentage supplied from LED arrays during cultivation in a controlled environment.

The total anthocyanin concentration was enhanced in arugula, kale, and red cabbage in response to an increased proportion of blue light (Fig. 5). In arugula, kale, and red cabbage, the total anthocyanin levels were, respectively, $70 \%, 65 \%$, and $75 \%$ greater in microgreens cultivated under $30 \%$ blue light than under the $5 \%$ blue light treatment. Total anthocyanin concentrations in mustard were similar for all LED treatments and were unaffected by the percentage of blue light. At its maximum, the absolute anthocyanin concentration in mustard microgreens was 1.7- to 18.6-fold that of the highest levels detected in the other three microgreens.

Nitrate concentration. The concentration of extractable nitrate was unaffected by the percentage of blue light supplied by the LED array, regardless of microgreen species (Table 1). The nitrate levels detected across all microgreens and their LED light quality treatments were between 0.10 and 0.72 $\mathrm{mg} \cdot \mathrm{g}^{-1} \mathrm{FW}$. The average level was greatest in red cabbage and least in arugula, with regard to the extractable nitrate concentration.

\section{Discussion}

Effect of varying blue light percentages in red:blue LED lighting on the concentrations of total chlorophyll, carotenoid, and nitrate concentrations in microgreens. The percentage of blue light supplied by LEDs did not affect the total chlorophyll in the four microgreen species. The impact of blue light on chlorophyll levels in plants during early development seems to be species-dependent. Similarly, chlorophyll levels in impatiens, salvia, and tomato are unaffected by blue light percentages in the range of $6 \%$ to $50 \%$ supplied by red:blue LEDs (Wollaeger and 


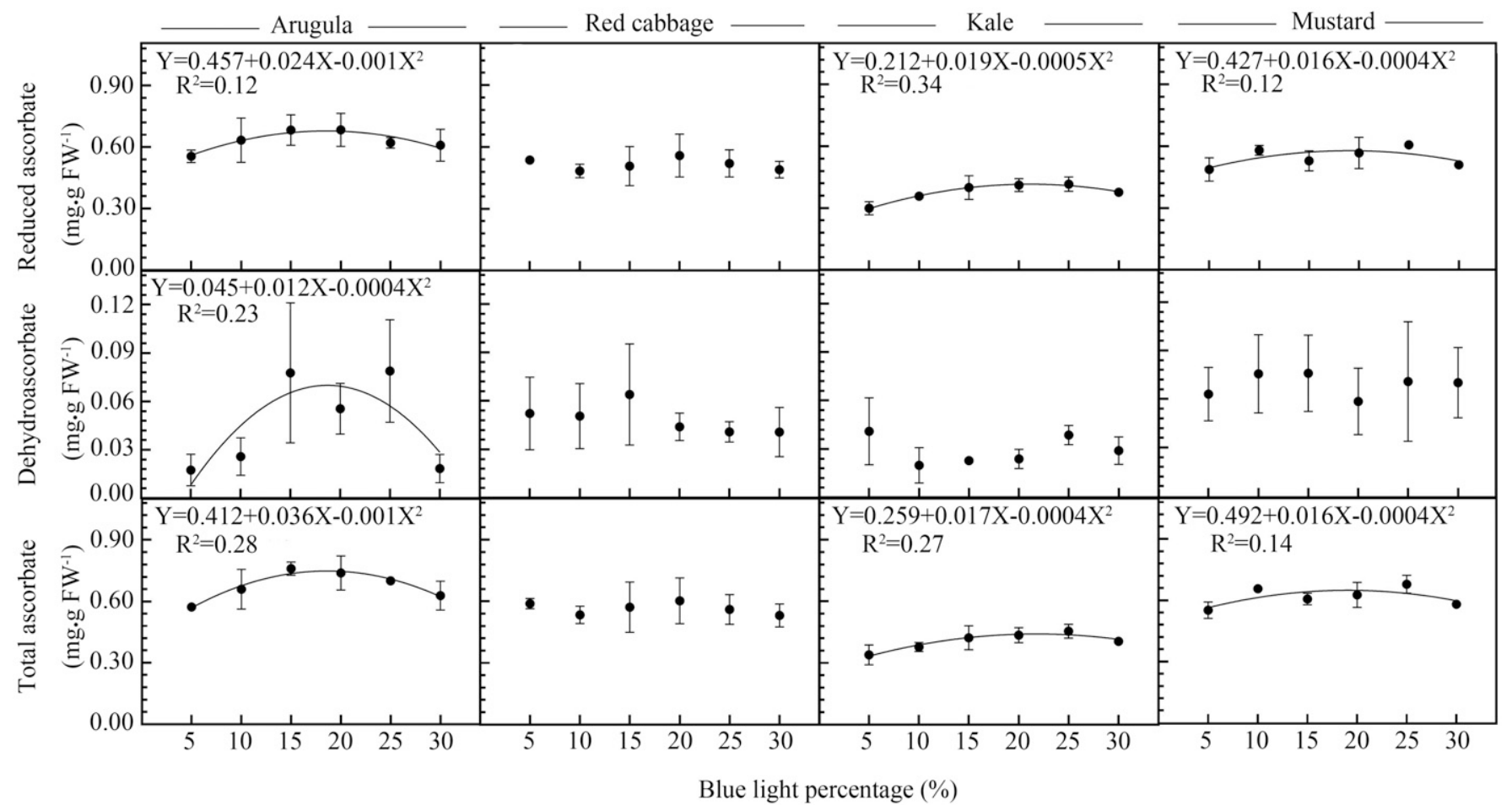

Fig. 3. The impact of light quality on reduced ascorbate, dehydroascorbate, and total ascorbate concentrations of arugula (Eruca sativa L.), 'Red Russian' kale [Brassica napus L. subsp. napus var. pabularia (DC.) Alef.], 'Mizuna' mustard (Brassica juncea L.), and red cabbage (Brassica oleracea L. var. capitata f. rubra). In all cases, microgreens were cultivated under a constant photosynthetic photon flux density of $300 \mu \mathrm{mol} \cdot \mathrm{m}^{-2} \cdot \mathrm{s}^{-1}$ with varying percentages of blue light. Data represent the mean \pm SE of three separate experiments. A nonlinear regression line represented by a solid black line is shown where the effect of the blue light percentage was significant at $P \leq 0.05 . R^{2}$ represents the corresponding determination coefficient.

Runkle, 2015); they are unaffected in spinach (Spinacia oleracea L.) when cultivated at blue light greater than 10\% (Matsuda et al., 2007). Conversely, cucumber seedlings accumulate more chlorophyll when blue light is increased from $0 \%$ to $50 \%$ in blue:red LEDs (Hogewoning et al., 2010). For lettuce, the total chlorophyll concentration is cultivardependent because the levels of this photosynthetic pigment increase in the red-leaf lettuce cultivar 'Sunmang' when the proportion of blue light is increased from $10 \%$ to $20 \%$; in comparison, the green-leaf lettuce cultivar 'Grand Rapid TBR' is unaffected in the same manner (Son and Oh, 2015). Chlorophyll biosynthesis is regulated by blue light photoreceptors (i.e., cryptochrome) as well as phytochrome proteins that interact with red and far-red light (Liu et al., 2017; Zheng et al., 2019). In our study, the increased supply of blue light to indoor-grown microgreens corresponded with a decreased supply of red light from sole-source LEDs. The reduction in red light availability may have been instrumental in the lack of effect on chlorophyll production in all four microgreen species investigated because there is a precedence that red light at $660 \mathrm{~nm}$ promotes the activation of phytochrome B and, consequently, the involvement of this protein in chlorophyll biosynthesis (Kreslavski et al., 2018). Therefore, lowering the proportion of red light at the expense of enhancing that of blue light may have reduced the activation of phytochrome-mediated regulation of chlorophyll biosynthesis in the Brassicaceae microgreens investigated during this study.

The total carotenoid concentration was unaffected by the increased blue light percentage in this study, which is in accordance with the results of previous research of basil microgreens cultivated under- LEDs supplying varying proportions of blue light in the range of $33 \%$ to $67 \%$ (Lobiuc et al., 2017). However, the total carotenoid concentration increases in beet microgreens when blue light supplied from red:blue LEDs is increased from $0 \%$ to $33 \%$, but not in parsley or mustard microgreens (Samuoliene et al., 2017). As photosynthetic accessory pigments, carotenoids dissipate excess light energy by combining with singlet oxygen to prevent oxidative damage under high light (Jahns and Holzwarth, 2012). The possibility remains that, during the present study, there was no impact of blue light because microgreens were grown under the same $P P F D$ of $300 \mu \mathrm{mol} \cdot \mathrm{m}^{-2} \cdot \mathrm{s}^{-1}$. This $P P F D$ has been shown to be optimal for microgreen quality, including the detection of surface green coloration, and, hence, the lack of yellowing in microgreens (Jones-Baumgardt et al., 2019).

Nitrate is the main source of nitrogen that plant roots acquire from the soil and is involved, for example, in the synthesis of proteins and chlorophyll in plants (Marschner, 1995). However, an increased amount of dietary nitrate could have a negative impact on human health. In the present study, extractable nitrate levels were unaffected by LEDs generating varying propor- tions of blue light percentages, regardless of species. This is consistent with the results of a previous study of lettuce in which nitrate was found to be equivalent in $10 \%$ and $25 \%$ blue light delivered from red:blue LEDs at a $P P F D$ of $200 \mu \mathrm{mol} \cdot \mathrm{m}^{-2} \cdot \mathrm{s}^{-1}$ (Zhang et al., 2018). The nitrate levels in Brassicaceae microgreens are lower than the maximum nitrate levels that are allowable for foodstuffs in some global markets (European Union, 2011). The lack of the blue light effect on nitrate composition is in accordance with the observation that chlorophyll levels in all four Brassicaceae microgreens were not impacted by the proportion of blue light in our study. This association is likely because nitrate availability in leaves affects the biosynthesis of chlorophyll and its precursors (Wen et al., 2019). Previous research indicated that ascorbate:nitrate ratios $>1$ occur in some greenhouse-grown vegetables, and this comparison is postulated to serve as a measure of the nutritional value of horticultural products (Pokluda, 2006). In this study, the total ascorbate:nitrate ratio ranged between 0.8 and 6.3 across all four microgreen species and their blue light percentage treatments. In general, the average total ascorbate:nitrate ratios were 1.1 and 1.2 in red cabbage and kale, respectively; however, these ratios were higher in arugula and mustard, with averages of 2.2 and 4.1, respectively. It is worth mentioning that the greatest total ascorbate:nitrate ratio was apparent at $20 \%$ blue light for all four microgreens assessed during this study. Therefore, the Brassicaceae microgreens cultivated during 


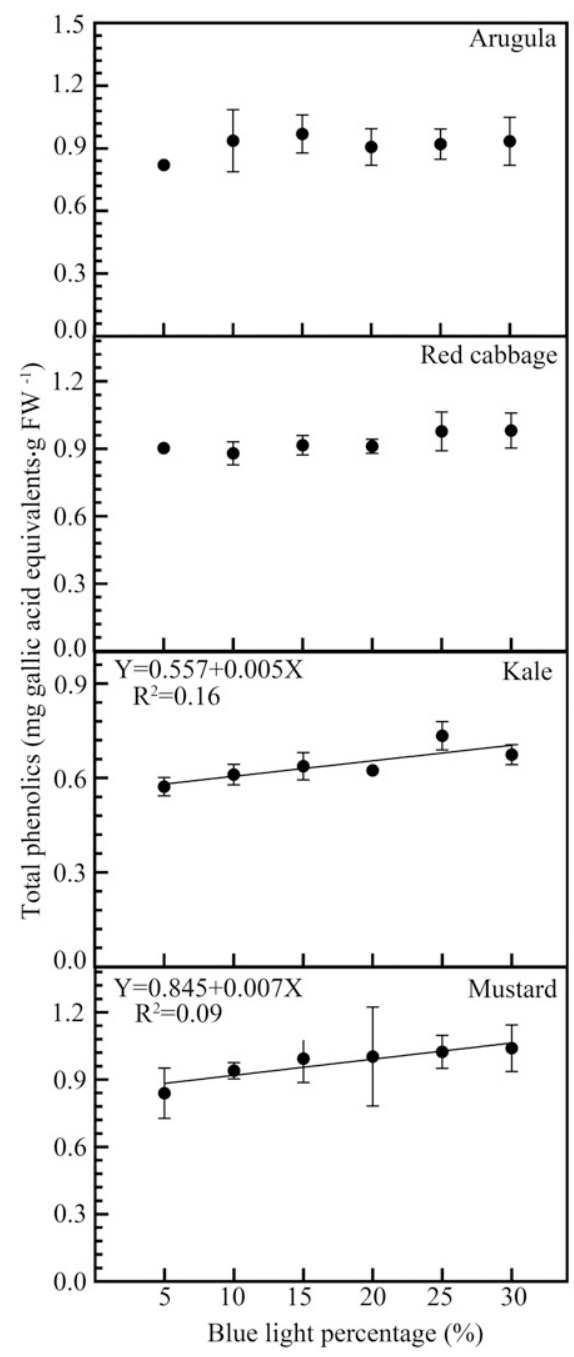

Fig. 4. The impact of light quality on total phenolic concentrations of arugula (Eruca sativa L.), 'Red Russian' kale [Brassica napus L. subsp. napus var. pabularia (DC.) Alef.], 'Mizuna' mustard (Brassica juncea L.), and red cabbage (Brassica oleracea L. var. capitata f. rubra). In all cases, microgreens were cultivated under a constant photosynthetic photon flux density of $300 \mu \mathrm{mol} \cdot \mathrm{m}^{-2} \cdot \mathrm{s}^{-1}$ with varying percentages of blue light. Data represent the mean $\pm \mathrm{SE}$ of three separate experiments. A linear regression line represented by a solid black line is shown where the effect of the blue light percentage was significant at $P \leq 0.05$. $R^{2}$ represents the corresponding determination coefficient.

the present study can be considered nutritious according to the Pokluda (2006) rationale.

Effect of blue light in red:blue LEDs on the concentrations of ascorbate, total phenolics, and total anthocyanins in microgreens. With the exception of red cabbage, the total and reduced ascorbate concentrations were elevated to a maximum in all microgreens with an increase in blue light (i.e., 20\% blue light) relative to the lowest proportion of $5 \%$. Our results mirror those of a previous study of lamb's lettuce (Valerianella locusta L.) in which ascorbate levels are greatest at $10 \%$ to $20 \%$ blue light supplied by LEDs in a greenhouse (Długosz-Grochowska

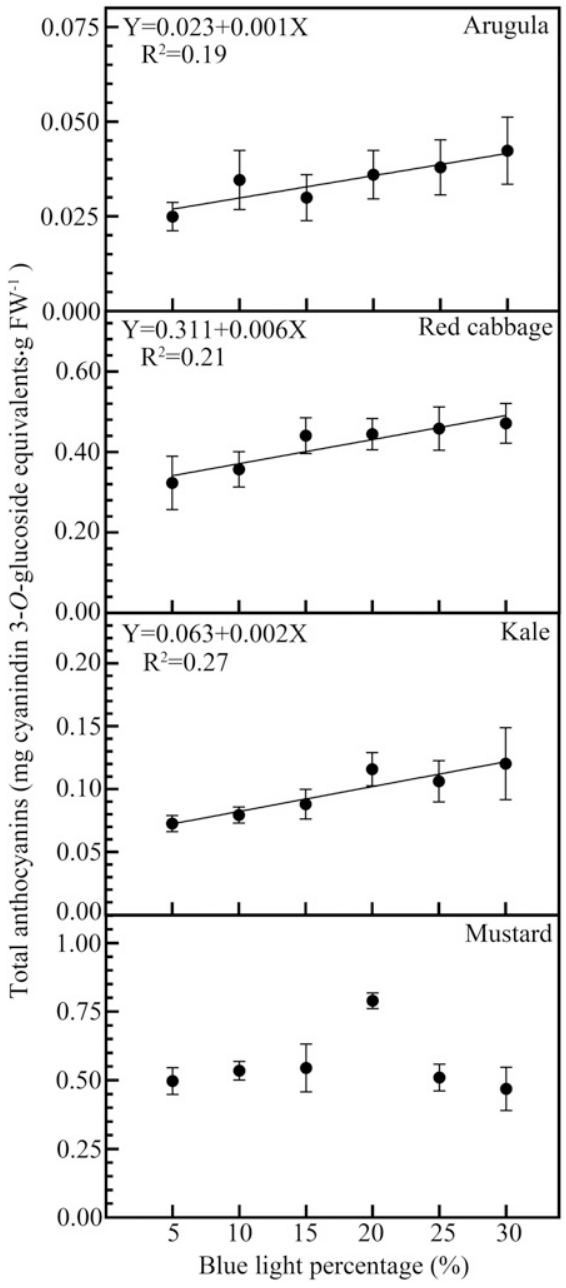

Fig. 5. The impact of light quality on total anthocyanin concentrations of arugula (Eruca sativa L.), 'Red Russian' kale [Brassica napus L. subsp. napus var. pabularia (DC.) Alef.], 'Mizuna' mustard (Brassica juncea L.), and red cabbage (Brassica oleracea $\mathrm{L}$. var. capitata $\mathrm{f}$. rubra). In all cases, microgreens were cultivated under a constant photosynthetic photon flux density of $300 \mu \mathrm{mol} \cdot \mathrm{m}^{-2} \cdot \mathrm{s}^{-1}$ with varying percentages of blue light. Data represent the mean \pm SE of three separate experiments. A linear regression line represented by a solid black line is shown where the effect of the blue light percentage was significant at $P \leq 0.05 . R^{2}$ represents the corresponding determination coefficient.

et al., 2017). The biosynthesis of ascorbate is dependent on the presence of light and its related biochemical processes, such as the photosynthetic electron transport pathway in leaf chloroplasts (Yabuta et al., 2007). It is known that increased proportions of blue light generated by LEDs increase photosynthesis (Hogewoning et al., 2010; Matsuda et al., 2004, 2007). Therefore, the accumulations of reduced and total ascorbate concentrations in the majority of microgreens could be due, in part, to the positive effect of blue light on photosynthesis; however, this physiological parameter was not assessed during this study. Regarding our study, the possibility remains that an increase in the proportion of blue light promotes increased gene expression and activity of enzymes operating in the ascorbate recycling pathway (e.g., ascorbate peroxidase) because these phenomena have been described for hydroponically grown lettuce seedlings under LEDs supplying $75 \%$ blue light relative to $25 \%$ red light (Zha et al., 2020). Interestingly, the aforementioned lettuce seedling study determined that an increase in the proportion of blue light does not alter the dehydroascorbate concentration. Similarly, the dehydroascorbate concentration was unchanged by the proportion of blue light for most of the Brassicaceae microgreens investigated during our study. The possibility remains that high dehydroascorbate levels in arugula microgreens at $15 \%$ to $20 \%$ blue light relative to all other treatments could be due to an impairment in the ascorbate recycling pathway.

Increased proportions of blue light promoted the accumulation of total phenolics in kale and mustard. Similarly, total phenolic concentrations in two lettuce cultivars are higher under $47 \%$ blue light generated by LEDs than plants cultivated under $0 \%$ to $13 \%$ and $0 \%$ to $35 \%$ blue light for 'Sunmang' cultivar and 'Grand Rapid TBR' cultivar, respectively (Son and Oh, 2013). However, total phenolics were unaffected by blue light in red cabbage and arugula microgreens in this study. These findings are consistent with the variable effect that red:blue LED ratios have on the concentration of total phenolics in acyanic and cyanic basil microgreens (Lobiuc et al., 2017). The increase in total phenolics with an elevation in the blue light percentage could be due to increased activity of phenylalanine ammonia-lyase, which is the initial step in the phenylpropanoid pathway leading to the production of flavonoids, including anthocyanins. In fact, high anthocyanin levels and phenylalanine ammonialyase activity are evident in the leaves of red curly lettuce grown under red LEDs supplemented with blue light relative to plants exposed to red or blue light alone (Heo et al., 2012).

An increased percentage of blue light in blue:red LED arrays proportionally increased the total anthocyanin concentration in arugula, kale, and red cabbage. Similarly, basil microgreens accumulate more anthocyanins under $50 \%$ and $66.7 \%$ blue light than under $33.3 \%$ blue light (Lobiuc et al., 2017). Overall, the accumulation of anthocyanins under an increased blue light percentage in the microgreens investigated during this study could be associated with more red coloration of microgreen cotyledons, which is a trait that was reported by a previous study (Ying et al., 2020). The increased levels of anthocyanins under a high percentage of blue light could be due to enhanced activities of key anthocyanin biosynthesis enzymes (e.g., anthocyanidin synthase) (Xu et al., 2014). Blue light promotes anthocyanin accumulation primarily through the action of cryptochromes, but it also requires active phytochrome proteins (Ahmad and Cashmore, 1997; Bouly et al., 2007; Kadomura-Ishikawa et al., 2013). It is 
Table 1. The impact of light quality on total nitrate concentrations of arugula (Eruca sativa L.), 'Red Russian' kale [Brassica napus L. subsp. napus var. pabularia (DC.) Alef.], 'Mizuna' mustard (Brassica juncea L.), and red cabbage (Brassica oleracea L. var. capitata f. rubra).

\begin{tabular}{|c|c|c|c|c|}
\hline \multirow[b]{2}{*}{ Blue light percentage $\mathrm{e}^{\mathrm{z}}$} & \multicolumn{4}{|c|}{ Nitrate $\left(\mathrm{mg} \cdot \mathrm{g}^{-1} \text { fresh wt }\right)^{\mathrm{y}}$} \\
\hline & Red cabbage & Kale & Arugula & Mustard \\
\hline $10 \%$ & $0.47 \pm 0.28$ & $0.39 \pm 0.33$ & $0.29 \pm 0.26$ & $0.27 \pm 0.10$ \\
\hline $20 \%$ & $0.44 \pm 0.28$ & $0.26 \pm 0.12$ & $0.41 \pm 0.37$ & $0.10 \pm 0.05$ \\
\hline $25 \%$ & $0.72 \pm 0.41$ & $0.29 \pm 0.17$ & $0.30 \pm 0.24$ & $0.22 \pm 0.11$ \\
\hline $30 \%$ & $0.61 \pm 0.33$ & $0.40 \pm 0.20$ & $0.31 \pm 0.25$ & $0.16 \pm 0.07$ \\
\hline
\end{tabular}

${ }^{\mathrm{z}}$ Microgreens were cultivated under a photosynthetic photon flux density of $300 \mu \mathrm{mol} \cdot \mathrm{m}^{-2} \cdot \mathrm{s}^{-1}$ with varying proportions of red light and blue light.

${ }^{\mathrm{y}}$ Data represent the mean $\pm \mathrm{SE}$ of three separate experiments.

tempting to speculate that cryptochromemediated upregulation of the anthocyanin biosynthesis pathway is involved in altering the levels of total anthocyanins in Brassicaceae microgreens.

Overall, for all Brassicaceae microgreens investigated during this study, the total chlorophyll, carotenoid, and nitrate concentrations were not altered by the percentage of blue light supplied by LEDs during cultivation under controlled environment. In contrast, the concentrations of extractable antioxidants, including total phenolics, reduced and total ascorbate, and total anthocyanin, were enhanced with increased proportions of blue light, although the magnitude of the effect on these phytochemicals and/or the blue light percentage(s) eliciting the maximal response varied across species. Therefore, apart from red cabbage, total ascorbate concentrations were lowest at $5 \%$ blue light, greatest at $20 \%$ blue light, and slightly lower at $30 \%$ blue light. An increased supply of blue light up to $30 \%$ was associated with the maximal accumulation of anthocyanins in arugula, kale, and red cabbage, but not for mustard. It is worth mentioning that total anthocyanin concentrations were only $4 \%$ to $15 \%$ lower at $20 \%$ blue light than at $30 \%$ blue light. Therefore, as a compromise, $20 \%$ blue light can be used for the cultivation of Brassicaceae microgreens containing high levels of ascorbate and anthocyanins.

\section{Literature Cited}

Ahmad, M. and A.R. Cashmore. 1997. The bluelight receptor cryptochrome 1 shows functional dependence on phytochrome A or phytochrome $\mathrm{B}$ in Arabidopsis thaliana. Plant J. 11:421-427, doi: 10.1046/j.1365-313X.1997.11030421.x.

Ainsworth, E.A. and K.M. Gillespie. 2007. Estimation of total phenolic content and other oxidation substrates in plant tissues using Folin-Ciocalteu reagent. Nat. Protoc. 2:875877, doi: $10.1038 /$ nprot.2007.102.

Bian, Z.H., Q.C. Yang, and W.K. Liu. 2015. Effects of light quality on the accumulation of phytochemicals in vegetables produced in controlled environments: A review. J. Sci. Food Agr. 95:869-877, doi: 10.1002/jsfa.6789.

Bouly, J.P., E. Schleicher, M. Dionisio-Sese, F. Vandenbussche, D. Van Der Straeten, N. Bakrim, S. Meier, A. Batschauer, P. Galland, R. Bittl, and M. Ahmad. 2007. Cryptochrome blue light photoreceptors are activated through interconversion of flavin redox states. J. Biol. Chem. 282:93839391, doi: 10.1074/jbc.M609842200.

Bourget, C.M. 2008. An introduction to lightemitting diodes. HortScience 43:1944-1946, doi: 10.21273/HORTSCI.43.7.1944.
Darko, E., P. Heydarizadeh, B. Schoefs, and M.R. Sabzalian. 2014. Photosynthesis under artificial light: The shift in primary and secondary metabolism. Philos. Trans. R. Soc. B Lond. B Biol. Sci. 369:20130243, doi: 10.1098/rstb.2013.0243.

Długosz-Grochowska, O., R. Wojciechowska, M. Kruczek, and A. Habela. 2017. Supplemental lighting with LEDs improves the biochemical composition of two Valerianella locusta (L.) cultivars. Hort. Environ. Biotechnol. 58:441449, doi: 10.1007/s13580-017-0300-4.

Dou, H., G. Niu, M. Gu, and J.G. Masabni. 2017. Effects of light quality on growth and phytonutrient accumulation of herbs under controlled environments. Horticulturae 3:36, doi: 10.3390/ horticulturae3020036.

European Union. 2011. Commission Regulation (EU) No 1258/2011 of 2 Dec. 2011 amending Regulation (EC) No $1881 / 2006$ as regards maximum levels for nitrates in foodstuffs. Off. J. Eur. Union 320:15-17.

Flaherty, E.J., G.B. Lum, J.R. Deell, S. Subedi, B.J. Shelp, and G.G. Bozzo. 2018. Metabolic alterations in postharvest pear fruit as influenced by 1-methylcyclopropene and controlled atmosphere storage. J. Agr. Food Chem. 66:1298912999, doi: 10.1021/acs.jafc.8b04912.

Hachiya, T. and Y. Okamoto. 2017. Simple spectroscopic determination of nitrate, nitrite, and ammonium in Arabidopsis thaliana. Bio Protoc. 7:1-13, doi: 10.21769/BioProtoc.2280.

Heo, J.W., D.H. Kang, H.S. Bang, S.G. Hong, C. Chun, and K.K. Kang. 2012. Early growth, pigmentation, protein content, and phenylalanine ammonia-lyase activity of red curled lettuces grown under different lighting conditions. Korean J. Hort. Sci. Technol. 30:6-12, doi: 10.7235/hort.2012.11118.

Hoffmann, A.M., G. Noga, and M. Hunsche. 2016. Alternating high and low intensity of blue light affects PSII photochemistry and raises the contents of carotenoids and anthocyanins in pepper leaves. Plant Growth Regulat. 79:275285, doi: 10.1007/s10725-015-0132-0.

Hogewoning, S.W., G. Trouwborst, H. Maljaars, H. Poorter, W. van Ieperen, and J. Harbinson. 2010. Blue light dose-responses of leaf photosynthesis, morphology, and chemical composition of Cucumis sativus grown under different combinations of red and blue light. J. Expt. Bot. 61:3107-3117, doi: 10.1093/jxb/erq132.

Jahns, P. and A.R. Holzwarth. 2012. The role of the xanthophyll cycle and of lutein in photoprotection of photosystem II. Biochim. Biophys. Acta Bioenerg. 1817:182-193, doi: 10.1016/j.bbabio. 2011.04.012.

Jones-Baumgardt, C., D. Llewellyn, Q. Ying, and Y. Zheng. 2019. Intensity of sole-source light-emitting diodes affects growth, yield, and quality of Brassicaceae microgreens. HortScience 54:1168-1174, doi: 10.21273/HORTSCI13788-18.

Kadomura-Ishikawa, Y., K. Miyawaki, S. Noji, and A. Takahashi. 2013. Phototropin 2 is involved in blue light-induced anthocyanin accumulation in Fragaria x ananassa fruits. J. Plant Res. 126:847-857, doi: 10.1007/s10265-0130582-2.

Kreslavski, V.D., D.A. Los, F.J. Schmitt, S.K. Zharmukhamedov, V.V. Kuznetsov, and S.I. Allakhverdiev. 2018. The impact of the phytochromes on the photosynthetic processes. Biochim. Biophys. Acta Bioenerg. 1859:400-408, doi: 10.1016/j.bbabio.2018.03.003.

Li, H., C. Tang, and Z. Xu. 2013. The effects of different light qualities on rapeseed (Brassica napus L.) plantlet growth and morphogenesis in vitro. Scientia Hort. 150:117-124, doi: 10.1016/j.scienta.2012.10.009.

Li, Q. and C. Kubota. 2009. Effects of supplemental light quality on growth and phytochemicals of baby leaf lettuce. Environ. Exp. Bot. 67:5964, doi: 10.1016/j.envexpbot.2009.06.011.

Lichtenthaler, H.K. and C. Buschmann. 2001. Chlorophylls and carotenoids: Measurement and characterization by UV-VIS spectroscopy. Curr. Protoc. Food Anal. Chem. 1:F4.3.1F4.3.8. https://doi.org/10.1002/0471142913.faf 0403s 01 .

Liu, X., Y. Li, and S. Zhong. 2017. Interplay between light and plant hormones in the control of Arabidopsis seedling chlorophyll biosynthesis. Front. Plant Sci. 8:1433, doi: 10.3389/ fpls.2017.01433.

Lobiuc, A., V. Vasilache, M. Oroian, T. Stoleru, M. Burducea, O. Pintilie, and M.M. Zamfirache. 2017. Blue and red LED illumination improves growth and bioactive compounds contents in acyanic and cyanic Ocimum basilicum L. microgreens. Molecules 22:2111, doi: 10.3390/molecules 22122111.

Machha, A. and A.N. Schechter. 2012. Inorganic nitrate: A major player in the cardiovascular health benefits of vegetables? Nutr. Rev. 70:367-372, doi: 10.1111/j.1753-4887.2012.00477.x.

Macknight, R.C., W.A. Laing, S.M. Bulley, R.C. Broad, A.A.T. Johnson, and R.P. Hellens. 2017. Increasing ascorbate levels in crops to enhance human nutrition and plant abiotic stress tolerance. Curr. Opin. Biotechnol. 44:153-160, doi: 10.1016/j.copbio.2017.01.011.

Marschner, H. 1995. Mineral nutrition of higher plants. Academic Press, London.

Massa, G.D., H.H. Kim, R.M. Wheeler, and C.A. Mitchell. 2008. Plant productivity in response to LED lighting. HortScience 43:1951-1956, doi: 10.21273/HORTSCI.43.7.1951.

Matsuda, R., K. Ohashi-Kaneko, K. Fujiwara, E. Goto, and K. Kurata. 2004. Photosynthetic characteristics of rice leaves grown under red light with or without supplemental blue light. Plant Cell Physiol. 45:1870-1874, doi: $10.1093 / \mathrm{pcp} / \mathrm{pch} 203$.

Matsuda, R., K. Ohashi-Kaneko, K. Fujiwara, and K. Kurata. 2007. Analysis of the relationship between blue-light photon flux density and the photosynthetic properties of spinach (Spinacia 
oleracea L.) leaves with regard to the acclimation of photosynthesis to growth irradiance. Soil Sci. Plant Nutr. 53:459-465, doi: 10.1111/ j.1747-0765.2007.00150.x.

McCree, K.J. 1972. The action spectrum, absorptance and quantum yield of photosynthesis in crop plants. Agr. Meteorol. 9:191-216, doi: 10.1016/0002-1571(71)90022-7.

Mensinga, T.T., G.J.A. Speijers, and J. Meulenbelt. 2003. Health implications of exposure to environmental nitrogenous compounds. Toxicol. Rev. 22:41-51, doi: 10.2165/00139709200322010-00005.

Pinto, E., A.A. Almeida, A.A. Aguiar, and I.M.P.L.V.O. Ferreira. 2015. Comparison between the mineral profile and nitrate content of microgreens and mature lettuces. J. Food Compos. Anal. 37:38-43, doi: 10.1016/j.jfca.2014.06.018.

Pokluda, R. 2006. An assessment of the nutritional value of vegetables using an ascorbate-nitrate index. Veg. Crops Res. Bull. 64:29-37.

Queval, G. and G. Noctor. 2007. A plate reader method for the measurement of NAD, NADP, glutathione, and ascorbate in tissue extracts: Application to redox profiling during Arabidopsis rosette development. Anal. Biochem. 363:58-69, doi: 10.1016/j.ab.2007.01.005.

Rao, A.V. and L.G. Rao. 2007. Carotenoids and human health. Pharmacol. Res. 55:207-216, doi: 10.1016/j.phrs.2007.01.012.

Roepke, J. and G.G. Bozzo. 2015. Arabidopsis thaliana $\beta$-glucosidase BGLU15 attacks flavonol 3- $O$ - $\beta$-glucoside-7- $O$ - $\alpha$-rhamnosides. Phytochemistry 109:14-24, doi: 10.1016/ j.phytochem.2014.10.028.

Samuolienè, G., A. Viršilè, A. Brazaitytè, J. Jankauskienè, S. Sakalauskienè, V. Vaštakaite, A. Novičkovas, A. Viškelienè, A. Sasnauskas, and P. Duchovskis. 2017. Blue light dosage affects carotenoids and tocopherols in microgreens. Food Chem. 228:50-56, doi: 10.1016/ j.foodchem.2017.01.144.

Siegelman, H.W. and S.B. Hendricks. 1958. Photocontrol of anthocyanin synthesis in apple skin. Plant Physiol. 33:185-190, doi: 10.1104/ pp.33.3.185.

Son, K.H. and M.M. Oh. 2013. Leaf shape, growth, and antioxidant phenolic compounds of two lettuce cultivars grown under various combinations of blue and red light-emitting diodes. HortScience 48:988-995, doi: 10.21273/ HORTSCI.48.8.988.

Son, K.H. and M.M. Oh. 2015. Growth, photosynthetic and antioxidant parameters of two lettuce cultivars as affected by red, green, and blue lightemitting diodes. Hort. Environ. Biotechnol. 56:639-653, doi: 10.1007/s13580-015-1064-3.

Tanaka, M., T. Takamura, H. Watanabe, M. Endo, T. Yanagi, and K. Okamoto. 1998. In vitro growth of Cymbidium plantlets cultured under super bright red and blue light-emitting diodes (LEDs). J. Hort. Sci. Biotechnol. 73:39-44, doi: 10.1080/14620316.1998.11510941.

Thoma, F., A. Somborn-Schulz, D. Schlehuber, V. Keuter, and G. Deerberg. 2020. Effects of light on secondary metabolites in selected leafy greens: A review. Front. Plant Sci. 11:497, doi: 10.3389/fpls.2020.00497.

Treadwell, D.D., R. Hochmuth, L. Landrum, and W. Laughlin. 2016. Microgreens: A new specialty crop. Univ. Florida IFAS Ext. HS1164.

Wen, B., C. Li, X. Fu, D. Li, L. Li, X. Chen, H. Wu, X. Cui, X. Zhang, H. Shen, W. Zhang, W. Xiao, and D. Gao. 2019. Effects of nitrate deficiency on nitrate assimilation and chlorophyll synthesis of detached apple leaves. Plant Physiol. Biochem. 142:363-371, doi: 10.1016/j.plaphy. 2019.07.007.

Wollaeger, H.M. and E.S. Runkle. 2015. Growth and acclimation of impatiens, salvia, petunia, and tomato seedlings to blue and red light. HortScience 50:522-529, doi: 10.21273/ HORTSCI.50.4.522.

Xiao, Z., G.E. Lester, Y. Luo, and Q. Wang. 2012. Assessment of vitamin and carotenoid concentrations of emerging food products: Edible microgreens. J. Agr. Food Chem. 60:7644 7651, doi: 10.1021/jf300459b.

Xiao, Z., S.R. Rausch, Y. Luo, J. Sun, L. Yu, Q Wang, P. Chen, L. Yu, and J.R. Stommel. 2019. Microgreens of Brassicaceae: Genetic diversity of phytochemical concentrations and antioxidant capacity. Lebensm. Wiss. Technol. 101:731-737, doi: 10.1016/j.lwt.2018.10.076.

$\mathrm{Xu}$, F., S. Cao, L. Shi, W. Chen, X. Su, and Z. Yang. 2014. Blue light irradiation affects an- thocyanin content and enzyme activities involved in postharvest strawberry fruit. J. Agr. Food Chem. 62:4778-4783, doi: 10.1021/ jf501120u.

Yabuta, Y., T. Mieda, M. Rapolu, A. Nakamura, T. Motoki, T. Maruta, K. Yoshimura, T Ishikawa, and S. Shigeoka. 2007. Light regulation of ascorbate biosynthesis is dependent on the photosynthetic electron transport chain but independent of sugars in Arabidopsis. J. Expt. Bot. 58:2661-2671, doi: 10.1093/jxb/ erm 124.

Yeh, N. and J.P. Chung. 2009. High-brightness LEDs-Energy efficient lighting sources and their potential in indoor plant cultivation. Renew. Sustain. Energy Rev. 13:2175-2180, doi: 10.1016/j.rser.2009.01.027.

Ying, Q., Y. Kong, C. Jones-Baumgardt, and Y. Zheng. 2020. Responses of yield and appearance quality of four Brassicaceae microgreens to varied blue light proportion in red and blue light-emitting diodes lighting. Scientia Hort. 259:108857, doi: 10.1016/j.scienta.2019.108857.

Zha, L., W. Liu, Q. Yang, Y. Zhang, C. Zhou, and M. Shao. 2020. Regulation of ascorbate accumulation and metabolism in lettuce by the red:blue ratio of continuous light using LEDs. Front. Plant Sci. 11:704, doi: 10.3389/fpls.2020. 00704.

Zhang, H. and R. Tsao. 2016. Dietary polyphenols, oxidative stress and antioxidant and antiinflammatory effects. Curr. Opin. Food Sci. 8:33-42, doi: 10.1016/j.cofs.2016.02.002.

Zhang, Y.J., R.Y. Gan, S. Li, Y. Zhou, A.N. Li, D.P. Xu, and H.B. Li. 2015. Antioxidant phytochemicals for the prevention and treatment of chronic diseases. Molecules 20:21138-21156, doi: 10.3390/molecules201219753.

Zhang, T., Y. Shi, F. Piao, and Z. Sun. 2018. Effects of different LED sources on the growth and nitrogen metabolism of lettuce. Plant Cell Tissue Organ Cult. 134:231-240, doi: 10.1007/ s11240-018-1415-8.

Zheng, L., H. He, and W. Song. 2019. Application of light-emitting diodes and the effect of light quality on horticultural crops: A review. HortScience 54:1656-1661, doi: 10.21273/HORTSCI 14109-19. 